\title{
Instrumental Meteorological Records Before 1850 An Inventory
}

Adapted from "Unlocking pre1850 Instrumental Meteorological Records: A Global Inventory," by Stefan Brönnimann (University of Bern), Rob Allan, Linden Ashcroft, Saba Baer, Mariano Barriendos, Rudolf Brázdil, Yuri Brugnara, Manola Brunet, Michele Brunetti, Barbara Chimani, Richard Cornes, Fernando Domínguez-Castro, Janusz Filipiak, Dimitra Founda, Ricardo García Herrera, Joelle Gergis, Stefan Grab, Lisa Hannak, Heli Huhtamaa, Kim S. Jacobsen, Phil Jones, Sylvie Jourdain, Andrea Kiss, Kuanhui Elaine Lin, Andrew Lorrey, Elin Lundstad, Jürg Luterbacher, Franz Mauelshagen, Maurizio Maugeri, Nicolas Maughan, Anders Moberg, Raphael Neukom, Sharon Nicholson, Simon Noone, Øyvind Nordli, Kristín Björg Ólafsdóttir, Petra R. Pearce, Lucas Pfister, Kathleen Pribyl, Rajmund Przybylak, Christa Pudmenzky, Dubravka Rasol, Delia Reichenbach, Ladislava Řezníčková, Fernando S. Rodrigo, Christian Rohr, Oleg Skrynyk, Victoria Slonosky, Peter Thorne, Maria Antónia Valente, José M. Vaquero, Nancy E. Westcott, Fiona Williamson,

Przemysław Wyszyński. Published in BAMS online, December 2019.

For the full, citable article, see DOI:10.1175/BAMS-D-19-0040.1. limate data are part of our cultural heritage. Enlightenment scientists initiated regular meteorological measurements in the seventeenth and eighteenth centuries, providing modern scientists a wealth of early weather and climate information from across the world. Very long temperature and rainfall series are widely used as a baseline for current changes and to study past climatic variations at regional scale. But records like these constitute only a subset of all measurements taken. We provide here a partial inventory of meteorological measurements made prior to around 1850. Numerous efforts by individuals, weather services, international projects, and the Atmospheric Circulation Reconstructions over the Earth Initiative (ACRE) form the basis of this inventory.

Interest in such historical weather data is not new. Scientists in the early eighteenth century compiled meteorological data in their efforts to study and understand weather and climate in different parts of the world. Numerous inventories were compiled in the nineteenth and early twentieth centuries, and data were used for regional climate descriptions or isothermal maps. Although more recent attempts have been made to systematically compile eighteenth-century records, most historical inventories have been forgotten, mainly because the metadata from these inventories have never been digitized.

Historical reanalyses such as the Twentieth Century Reanalysis (20CR) are able to generate useful weather reconstructions from 


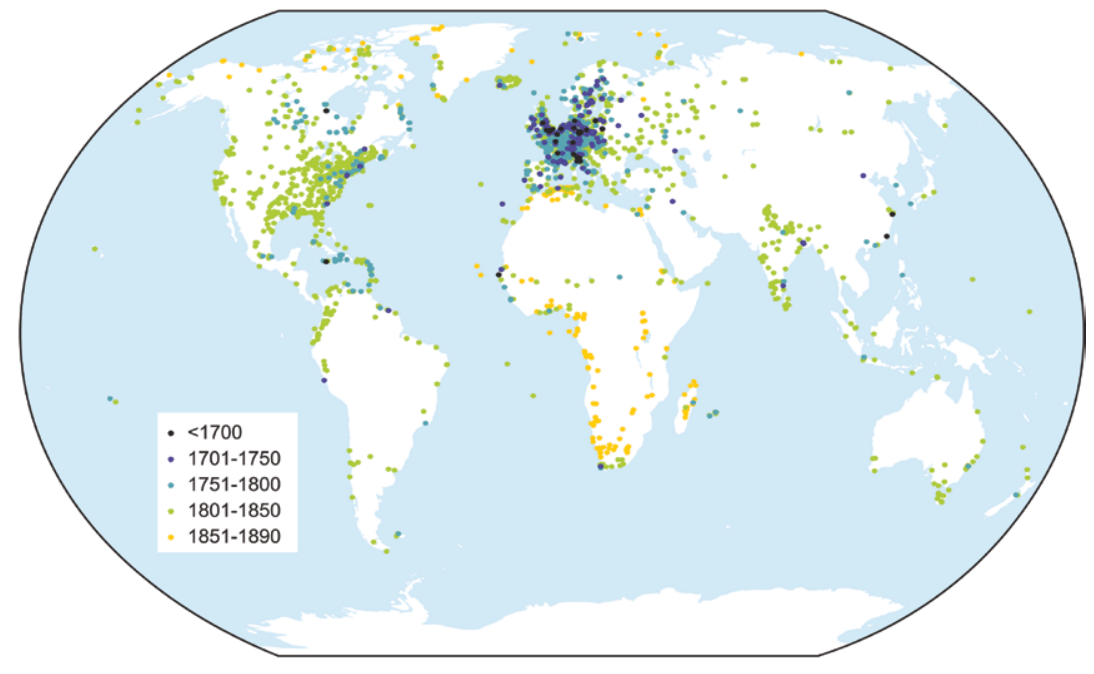

records of only a few years, though long-term homogeneity of such short records is problematic. A backward extension of both climate and weather data contributes toward a better understanding of extreme, and thus rare, events. It allows important climate processes to be addressed, such as the transit out of Little Ice Age climate, the impacts of volcanic eruptions, or natural interannual-to-decadal variability. However, this requires rescuing additional historical weather data. Together with other sources, reanalyses also allow climate data to be connected with climatic impacts and associated societal responses.

The initial systematic global compilation of information on early instrumental data in this article documents efforts within ACRE and the International Surface Temperature Initiative, as well as results from a 2018 workshop held in Bern, Switzerland. The focus is on instrumental series with regular (daily or more frequent) measurements over at least one year prior to 1850 , even if some of the data have so far not been found. The inventory contains the relevant meta information when and where available as well as information on availability or state of data rescue. Though far from complete, this inventory, along with data rescue services, aims to support future data rescue efforts and should help to counteract the danger of losing data.

\section{Methods}

We defined 1850 as a cut-off year because it approximately reflects the start of national weather services and therefore broadly the beginning of international standards. For the same reason, many global datasets reach back to around that time.
However, for some regions the 1850 cut-off is too early. Africa and the Arctic have almost no measurements prior to 1850 , while much data from the second half of the century have also never been systematically compiled. For these regions, we set a later cut-off at 1890 . Series that are listed in inventories published prior to 1850 but for which measurement years were not given are also included.

A second criterion is that only metadata on instrumental measurements were searched. We did not consider records with only wind observations or the
$\stackrel{\Delta}{*}$ The global coverage of entries in the inventory, tinted as a function of start year. Plotted duplicates lie on top of each other.

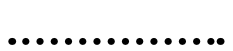

1) searching 5 global repositories that contained the series as well as some metadata, with 741 unique records found;

2) searching regional and national data repositories or metadata inventories, which comprised about 1,500 records (largely overlapping the global repositories);

3) compiling community knowledge, including through ACRE and the Bern workshop and through further involvement with the community, which was particularly important for regions not represented in repositories and for periods before the founding of national agencies;

4) compiling a number of early, nondigital, global and regional inventories (mostly metadata); and

5) compiling early collections made by scientists, including in early, coordinated networks.

The inventory should be able to store comprehensive meta information and also collect sparse information. The metadata collected include existing station identifications; station location; observer name and context, variables, and measurement frequency; the inventory in which it is contained; the start and end year and availability 
WMO Region 6: Europe. The first European measurements reach back to the seventeenth century, with good coverage of Central Europe by the first half of the eighteenth century. The records usually comprise temperature and pressure, and occasionally precipitation. Particularly dense coverage is reached in the $1780 \mathrm{~s}$. Although many series have been digitized, an even greater coverage could be reached for this period and for the first half of the eighteenth century. The United Kingdom has some of the earliest meteorological measurement series: The Central England temperature record reaches back to 1659 .
WMO Region 2: Asia. The first measurements in Asia are from China and date back to the late seventeenth century. Early records are also available for India, and the longest continuous series are rainfall in Seoul as well as temperature, pressure, and rainfall in Chennai, India, both dating back to the eighteenth century. Unlike Africa, Asian records report not only rainfall, but also pressure and temperature. Most records start after 1800. Various data rescue activities are underway, but many records have not yet been digitized.
WMO Region 1: Africa. The start of instrumental meteorological measurements in Africa varies greatly by country. Rainfall records generally go back further than temperature records, and mostly start after 1800 . Much of the series has already been digitized, but due to the sparse coverage, additional series are particularly valuable. Africa's oldest instrumental records come from South Africa, and elsewhere instrumental records concern mostly rainfall and were taken by colonial administrations. In some cases, regular measurements were made by missionaries or by individuals, and occasionally lengthy series were made during scientific expeditions. In general, the longest records are available for stations near the coast, with the far inland being nearly devoid of measurements until the twentieth century.

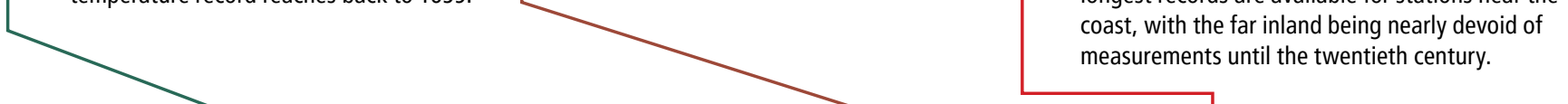

\section{Number of $* \triangleright$ \\ entries as a \\ function of \\ time and region \\ (the spikes in}

the nineteenth

century are due

to records with

unknown obser-

vation period).

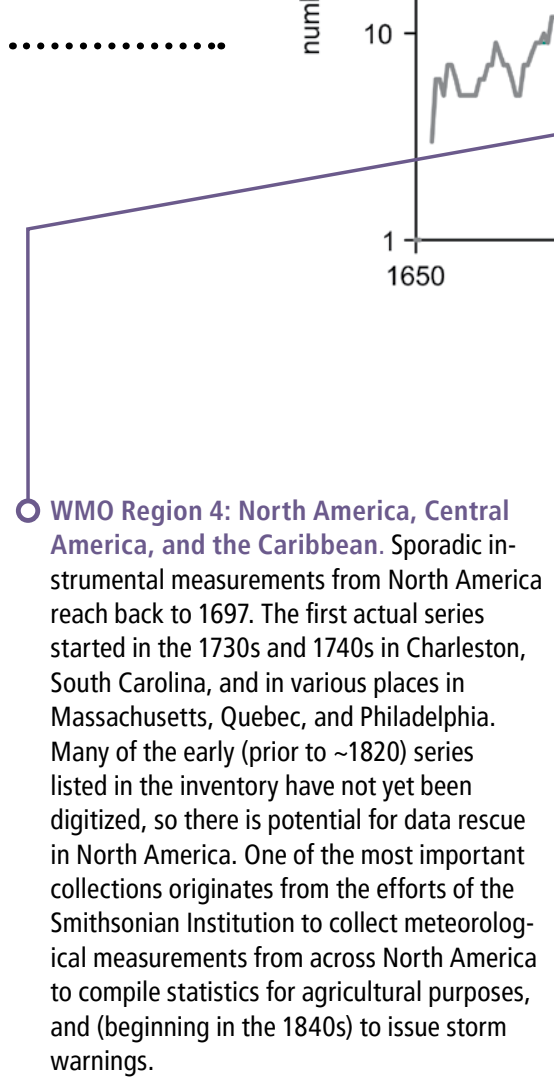

WMO Region 3: South America. The longest instrumental record from South America is temperature from Lima, Peru, which reaches back to 1754 but is only available as annual minimum and maximum temperatures. Almost all other records inventoried start after 1800. No systematic inventories are currently available, and data collected prior to the foundation of the National Meteorological Services are dispersed among a variety of archives. A recent effort retrieved more than 300,000 pre-1900 meteorological measurements from 20 countries in South and Central America, and identified some of the most relevant sources for the region.

Most of the series have gaps during the early nineteenth century - a period of wars of independence - and some original records likely were lost because many observatories were used for military proposes.
Arctic. The first instrumental observations in the Arctic, of at least three months duration, were initiated in 1767 in Greenland, and four years later in Labrador. Instrumental meteorological data from the four regular stations run by the Danish Meteorological Institute extend as far back as 1784 (although all series contain many gaps), and meteorological observations in the Canadian Arctic began in 1819 .
WMO Region 5: Southwest Pacific. Measurements from Malaysia and Singapore date back to the early nineteenth century, and land-based measurements for Australia date back to European settlement on the continent in 1788 and were taken primarily at the main colonial centers of population in southern Australia. However, other locations also kept records starting in the 1830 s. 
in present repositories; the status on digitizing and availability; and comments.

The coordinates were tested against station names, countries, and a land-sea mask, and errors were corrected. Duplicates were identified, suspicious series in the original sources were checked, and series starting after 1850 (or 1890 for Africa and the Arctic) were flagged.

Duplicate removal proved difficult. Often, duplication was only partial, and in such cases, both entries were left in. Some series were made up of multiple stations if within a certain distance, and some have overlapping periods. Some series have unique entries per variable, observer, or source; we did not attempt to unify this.

We provide two versions of the inventory: The "history" version contains all entries, including flagged entries that may contain errors; in the "clean version," all flagged entries are removed.

\section{Results}

The inventory currently has 10,349 entries, and 5,766 of those are flagged as duplicates, post-1850 (post-1890), or noninstrumental. The remaining 4,583 entries are from $\sim 2,250$ locations. There are still numerous partial duplicates. Almost all early and long series are from Europe, but long records also exist for New England and Canada. Early records from other WMO regions are sporadic and short, and are mostly from expeditions and colonial endeavors. Only after 1800 is nearly global coverage achieved, with continuous series in all WMO regions except Africa. For Africa and the Arctic, good coverage emerges only in the period 1851-90. (There is no entry for Antarctica.)

The first series start in the 1650s, with the number of records increasing to approximately 50 in 1720 and reaching the hundreds by 1800 . The increases in the early eighteenth century as well as the peak in the late eighteenth century indicate coordinated activities, while a 30\% drop in the late eighteenth century corresponds to the politically unstable Napoleonic period in Europe. A brief analysis shows that $\sim 25 \%$ of entry years are fully transcribed and another 25\% partly so. Only around $20 \%$ of entry years are available from global repositories, indicating that a considerable fraction of the transcribed data has not yet made it into these repositories.

\section{Conclusions}

This global inventory will support data compilation and data rescue efforts, and should provide the necessary information to prioritize data rescue

\section{$\equiv$ METADATA}

BAMS: What surprises you most about what you found?

Stefan Brönnimann: I am surprised by the large number of series prior to 1850 that we catalogued, and I am impressed by the compilation work climate scientists did in the mid-to-late nineteenth century — without computers or e-mail.

BAMS: Where did they get their data?

SB: Scientists, laymen, priests, officers, doctors, plantation owners, explorers, teachers, and missionaries: They all performed an enormous number of meteorological measurements in the eighteenth and nineteenth centuries- far more than I would ever have thought. Only the long, continuous series are well known today, but the numerous short records have now also become valuable.

BAMS: Where does this inventory lead?

SB: Unfortunately a lot of these records are nowadays forgotten, or have not yet made it to the digital era. New numerical methods are able to make use of them to reconstruct the daily weather. So we have to go back to the archives and revisit the meticulous work of these people.

efforts. The inventory of 4,583 (partly) unique entries from 2,250 locations is larger than we anticipated and suggests that climate or weather reconstruction (e.g., by means of reanalyses) based on instrumental data might be extended back well into the eighteenth century.

However, the data are not readily available. Roughly half of the series have not yet been transcribed, and of those that have been partly or fully transcribed, only half are represented in global inventories. Extending the data series backward thus requires further efforts, including cataloguing metadata, inventorying and updating current data holdings, maintaining and expanding data compilations, and enforcing data standards. The next steps for the community are therefore to 1 ) image and transcribe further early instrumental data and preserve them for posterity, and 2) compile the digitally available data in a common repository. Activities currently undertaken within the Copernicus Climate Change Services (C3S) can support this process with broader contributions from the communities. The inventory will be maintained as a living document at the C3S Climate Data Store, and additions to the inventory are welcomed. 
AMS titles now

available as eBooks

at springer.com

\section{AMS BOOKS}

\section{RESEARCH APPLICATIONS HISTORY}

www.ametsoc.org/amsbookstore

Springer

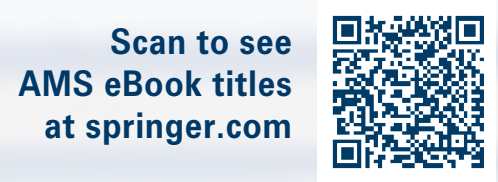

Springer

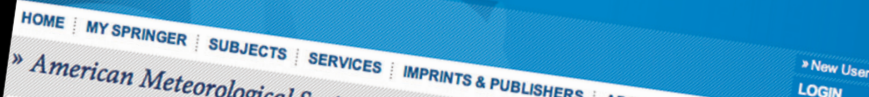

"American Meteorological SOCiety
"AOMTIN

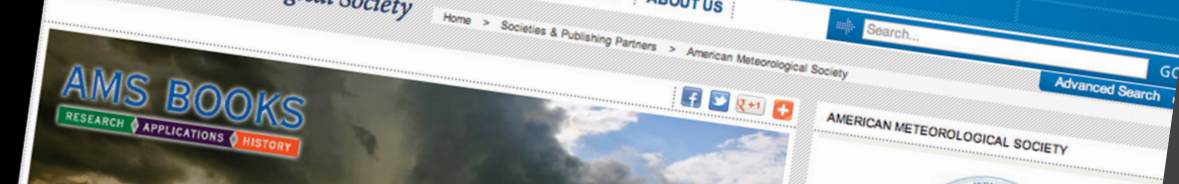

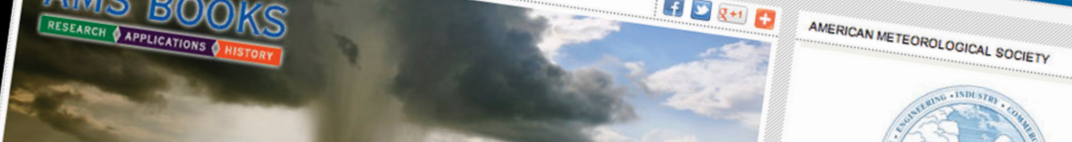

American Meteorol

Promoting the dewerogical Society

the atmos the deverap

the atmospheric and relont and disseminatb of

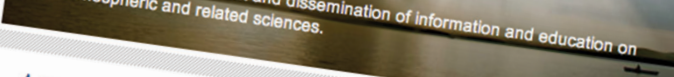

American Meteorological Society eB

AMS Books

published by the AMs a monograph publishing prent

shing program related to ho poer-

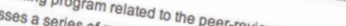

related to the as eBooks) as weil ar ariy out-ortprint vol metoorological and historica journals

to the atmospheric sciences a growing list of academis, which have been urough ographs

ind policy, and general-interest books

Sort listing by:

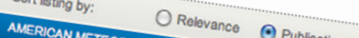

वध्ये Exporit to $\mathrm{CSO}$

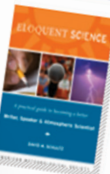

Eloquent Science

Bloquent Scie

A Practical Guite

Schulta, David
2009

Price from $\$ 45.00$

copyright Year

Avalobe

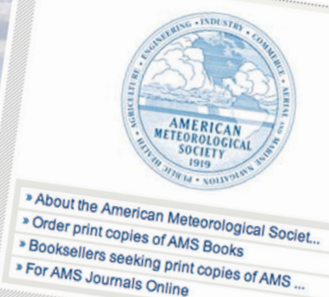

RESOURCES

Stay Informed

Receive notitication of now releases from
Books

Sub

AMS 